

\title{
Research Article Identification and Analysis of Off-grid Energy Sources Used at the Household Scale in Lubumbashi, DR Congo
}

\author{
1'Banza Wa Banza Bonaventure and ²Mbangu Tshingej Néné \\ ${ }^{1}$ School of Industrial Engineering, University of Lubumbashi, Lubumbashi BP 1825, DR Congo \\ ${ }^{2}$ Higher Institute of Applied Techniques, Lubumbashi, DR Congo
}

\section{Abstract}

Background and Objective: In Lubumbashi the electrical service is characterized by frequent load shedding, longer and unplanned. To overcome this situation, population of Lubumbashi is forced to resort to alternative energy sources. The main objective of this study was to identify and analyze the different energy sources used in household scale in Lubumbashi. Materials and Methods: A total of 5270 households were surveyed in the 26 districts grouped into 7 municipalities. Data from household surveys have been subjected to one-way analysis of variance (ANOVA) to highlight the differences between averages of municipalities. In addition, a Tukey post-hoc test was applied to determine the difference between the means for the result with a significant difference $(p<0.05)$. R 2.15 and past software were used for statistical analysis. Results: The results revealed 2 main sources of energy used for cooking, 4 for lighting and 3 as alternative sources of electricity. In the case of cooking, households mainly prefer charcoal than wood heaters. Only some households of outlying districts still use wood for cooking. These preferred sources however result in multiple negative consequences for both human health and the environment. Regarding the sources of energy for lighting, candles are the most preferred because of easy accessibility while producing poor quality light. In case of load shedding or lack of electricity, some households are implementing alternative sources such as the generator and solar panels. Indeed, the use of these sources varies from one to another, with a higher frequency of generator use. Conclusion: In this context, programs that would target improving and increasing access to sustainable and clean energy, should take account of geographical disparities due to population growth and sprawl of Lubumbashi.

Key words: Lubumbashi, alternative energy sources, charcoal, off-grid energy

Citation: Banza Wa Banza Bonaventure and Mbangu Tshingej Néné, 2019. Identification and analysis of off-grid energy sources used at the household scale in Lubumbashi, DR Congo. Asian J. Ind. Eng., 11: 1-7.

Corresponding Author: Banza Wa Banza Bonaventure, School of Industrial Engineering, University of Lubumbashi, Lubumbashi BP 1825, DR Congo Tel: $+32465171090 /+243992179805$

Copyright: @ 2019 Banza Wa Banza Bonaventure and Mbangu Tshingej Néné. This is an open access article distributed under the terms of the creative commons attribution License, which permits unrestricted use, distribution and reproduction in any medium, provided the original author and source are credited.

Competing Interest: The authors have declared that no competing interest exists. 


\section{INTRODUCTION}

Urbanization has become an integral part of the socio-economic growth of developing countries. Its levels vary across countries and continents but population growth is faster in cities than rural areas due to both natural increase and migration' ${ }^{1}$. Although urbanization and rising per capita incomes usually lead in intensive use of modern fuels, such as gas and electricity and a decline of the traditional biomass in developed cities ${ }^{2}$, this is not the case in many African cities ${ }^{3,4}$. In sub-saharan Africa for example, more than 600 million people are not connected to electricity grid ${ }^{5}$. Thus, Africa remains the least electrified region of all developing regions $s^{4,6}$. Approximately $85 \%$ of energy needs in sub-saharan Africa (excluding South Africa) are covered by wood use $\mathrm{e}^{6-9}$.

Although, the electricity access rate is $61.6 \%$ at urban scale in Lubumbashi, it is poor quality is deplorable ${ }^{10}$. Today in most developing cities, households opt for the use of multiple sources of energy which provides a sense of energy security. Indeed, the complete dependence on a single fuel or technology alone can make households vulnerable to price changes and unreliable service ${ }^{11}$. However, these energy security measures in most households are more expensive compared to the cost that would be required for a permanent access to electricity services ${ }^{12}$. Frequent load shedding in Ontario (Canada) for example, led households to use private generators to ensure continuous supply of electricity, resulting for them in additional costs. Such irregularities are counted in billions dollars in annual losses ${ }^{11}$. The analyze of various alternative sources of energy is an effective way to identify sustainable and recoverable resources. This study has the objective to identify and analyze various alternative energy sources used at the household level in Lubumbashi. The study verifies the hypothesis that households in Lubumbashi make the most use of unsustainable sources of energy.

\section{MATERIALS AND METHODS}

Study area: This study was carried out in the city of Lubumbashi, located in the Southeast of the country, at $11^{\circ} 40^{\prime}$ south latitude and $27^{\circ} 29^{\prime}$ east longitude. Administratively, the city is made up of 43 districts grouped into 7 communes ${ }^{13}$ namely: Lubumbashi, Kenya, Kampemba, Katuba, Kamalondo, Ruashi and Annexe.

The rate of access to electricity in Lubumbashi varies from a municipality to other. Municipalities with a high percentage of electrification are those located in the center of the city, namely Kenya and Kamalondo which record 80.4 and 79.7\%, respectively. In contrast, Annexe municipality grouping new districts has the lowest electrification rate. At the urban scale the current electricity access rate ${ }^{10}$ is over $60 \%$. Meanwhile, the number of hours and days of cuts per hour and per week is very high, which deteriorates the quality of service ${ }^{10}$.

Sampling and data collection: Random Sampling Method of Laminate (RSML) was chosen because this type of sampling (probability) provides a representative sample. Moreover, each individual in the population (household) has an equal probability of being included in the sample ${ }^{14-16}$. The surveys were conducted throughout the city and lasted 10 months, from July, 2016-May, 2017.

The size of the initial sample was obtained using the following equation:

$$
\mathrm{n}_{1}=\frac{\mathrm{z}^{2} \mathrm{P}(1-\mathrm{P})}{\mathrm{e}^{2}}
$$

where, $\mathrm{z}$ is the value type of confidence level, $\mathrm{P}$ is the proportion of the actual population and $\mathrm{e}$ is the margin of error.

The adjustment taking into account the size of the population $\mathrm{N}$, was made using the following equation:

$$
\mathrm{n}_{2}=\mathrm{n}_{1} \frac{\mathrm{N}}{\mathrm{N}+\mathrm{n}_{1}}
$$

Ultimately, the adjustment to the response rate to determine the final size of the sample, $n$ : Where $r$ is the expected response rate:

$$
\mathrm{n}=\frac{\mathrm{n}_{3}}{\mathrm{r}}
$$

where, $r$ is the expected response rate.

The final sample was well distributed among the strata (municipalities of the city). The proportion of the sample allocated to the stratum $h$ is $a_{h}=n_{h} / n$. In each stratum $h$, the sample size $n_{h}$ is equal to the result of the size of the total sample $\mathrm{n}$ and $\mathrm{h}$ the proportion of the sample from that particular stratum. As in the case of these investigations all strata were not the same size, an apportioning $\mathrm{N}$ was well used ${ }^{17}$, the sample size $\left(n_{h}\right)$ each stratum is proportional the population size $\left(N_{h}\right)$ of the stratum ${ }^{18}$. A larger share of the sample was therefore assigned a higher stratum on a smaller stratum. The following equation was obtained:

$$
\mathrm{n}_{\mathrm{h}}=\frac{\mathrm{N}_{\mathrm{h}}}{\mathrm{N}} \mathrm{n}
$$




\begin{tabular}{lcc}
\multicolumn{3}{l}{ Table 1: Determination of the sample size in the different municipalities } \\
\hline Strata & No. of households & Sample size \\
\hline Lubumbashi & 32357 & 740 \\
Kampemba & 48470 & 1110 \\
Kamalondo & 6499 & 148 \\
Kenya & 20496 & 470 \\
Katuba & 36976 & 846 \\
Ruashi & 41311 & 952 \\
Annexe & 43891 & 1004 \\
Total & 230000 & 5270 \\
\hline
\end{tabular}

The level of accuracy has been retained ${ }^{18}$ to $\pm 5 \%$, considering a margin of error of 0.05 , confidence level of $95 \%$ for each stratum and a response rate ${ }^{19}$ of $50 \%$. A total of 5270 households were surveyed in the 26 districts in 7 municipalities. In each municipality the number of households to be surveyed was previously defined (Table 1).

Data processing: The surveys consisted in identifying in the various households the presence/absence and the type of alternative sources of energy. The survey data were stripped and encoded in binary form using Excel software. After encoding, data were subjected to one-way analysis of variance (ANOVA) to highlight the differences between averages of municipalities ${ }^{20-24}$. In addition, a Tukey post-hoc test was applied to determine the difference between the means for the result with a significant difference $(p<0.05)^{20-24}$. The ANOVA allowed differentiating the means of the use of different energy sources. R 2.15 and Past software were used for statistical analysis.

\section{RESULTS}

Overall, in the city of Lubumbashi, the main source of electricity in case of failure or lack of electricity is the generator. It is clear from Fig. 1 that $29.2 \%$ of the surveyed population use the generator, $13.1 \%$ for the dynamo and only $3 \%$ for solar panels.

Taking into account the different municipalities of the city Lubumbashi, Fig. 2 reveals large disparities in the use of the generator. The highest percentage is observed in Ruashi municipality while the use of generators in Katuba and Kenya municipalities is lower (respectively 6.58 and $3.98 \%$ of the households).

Regarding the use of solar panels in the different municipalities of the city of Lubumbashi, Fig. 3 shows that Lubumbashi leads with $9.6 \%$ of households using this energy source. By cons in Kamalondo municipality, none of the surveyed uses the solar panel. In the new

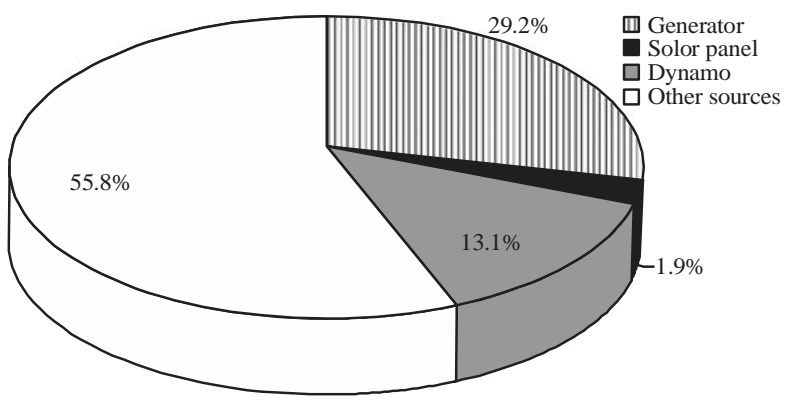

Fig. 1: Main sources of electrical energy in Lubumbashi

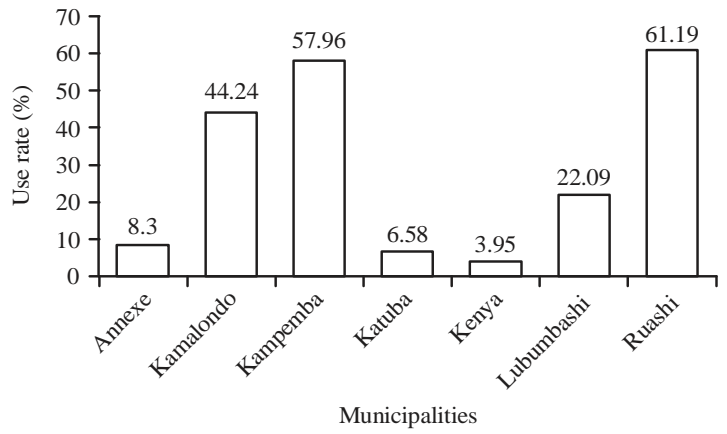

Fig. 2: Use of generators in the various municipalities

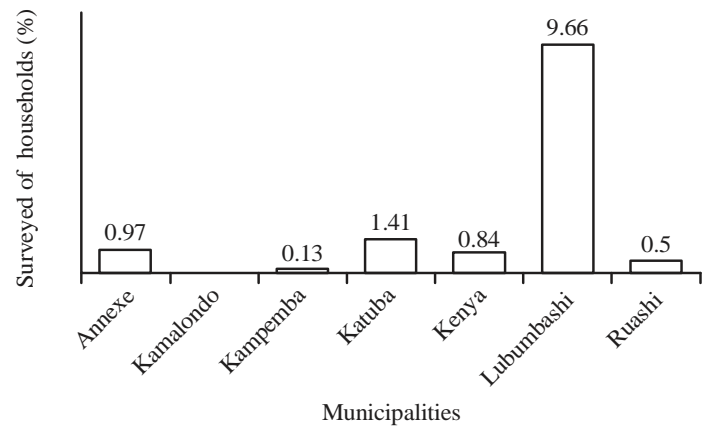

Fig. 3: Use of solar panels in the various municipalities

districts gathered in Annexe and Ruashi municipalities, the rate of panels use does not even reach $1 \%$.

Figure 4 shows the rate of dynamos use in 7 municipalities of the city of Lubumbashi. The highest percentage is observed in the Annexe municipality (30.46\%) while the lowest percentage is observed in Kamalondo municipality ( $0 \%$ ) where none of surveyed households use this energy source.

Examination of Fig. 5 shows clearly that candles are the most used in all municipalities of the city of Lubumbashi as a source of energy for lighting. The highest percentage is observed in Kamalondo municipality (100\%). 


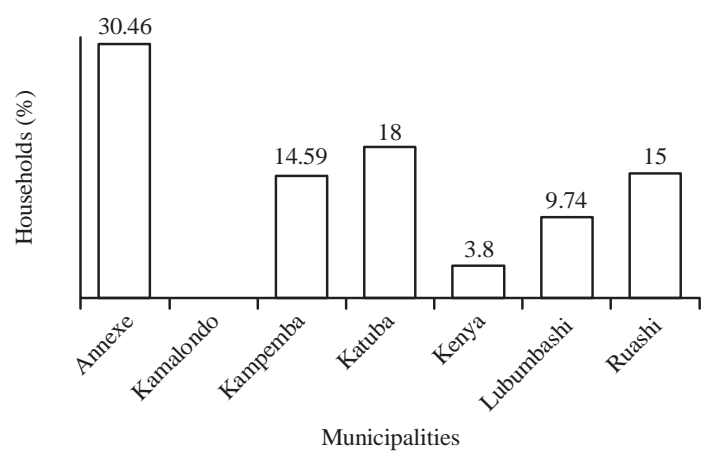

Fig. 4: Use of dynamo in the different municipalities

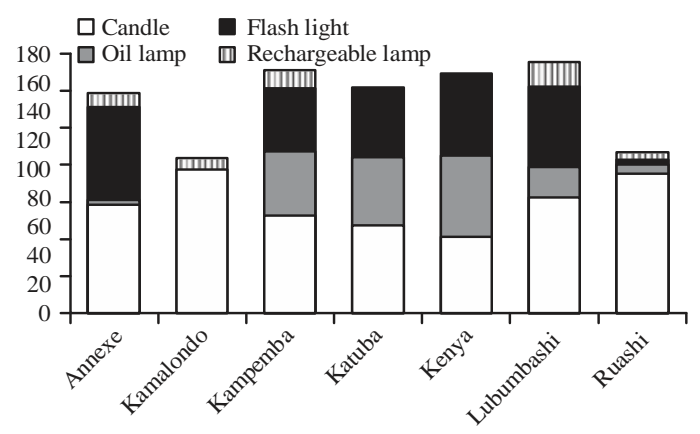

Fig. 5: Percentage of use of energy sources for lighting

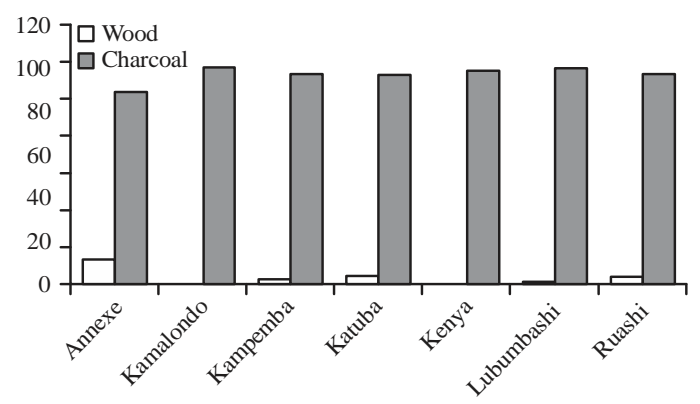

Fig. 6: Percentage of use of energy sources for cooking

Looking at Fig. 6, it turns out that charcoal is by far the most used source for cooking in all municipalities of the city of Lubumbashi. The wood is much used in Annexe municipality but in a small percentage ( $11 \%$ of households).

\section{DISCUSSION}

Lubumbashi is as most cities in developing countries characterized by the use of diverse energy sources in domestic scale. Most households (29.2\% of the surveyed population) use the generator, $13.1 \%$ using the dynamo and 3\% using solar panels. However, generator group use causes a financial cost for the purchase of fuel and maintenance. As for the dynamo, it is a heat engine coupled to an alternator. It is proved by the literature that the use of these alternative methods is more expensive compared to a direct connection to the electricity grid of SNEL. However, most households try to avoid frequent and unplanned load shedding. The use of several energy sources provides a sense of energy security. Indeed, the complete dependence on a single fuel or technology alone can make households vulnerable to price changes and unreliable service ${ }^{11}$.

Furthermore, the use of these different sources of electricity shows wide disparities in the seven municipalities of the city of Lubumbashi. Due to some geographic and socio-economic contexts, some municipalities use some sources more than others. As a result, among the municipalities of the city center some use less the generator unlike other. Although the municipality which records the highest percentage regarding the use of generators is constituted by new neighborhoods. Figure 2 showed, however, that Annexe municipality (also home to the recently born sprawl districts) presents small percentage (8.3\%). Compared to Ruashi, Annexe municipality gathers more new districts. Indeed, this municipality is mainly composed of a set of suburbs surrounding the city of Lubumbashi. In addition, this municipality comes from the spread of other municipalities. Regarding solar, Lubumbashi municipality leads with $9.6 \%$ of the households that use this energy source. By cons in Kamalondo municipality, none of the surveyed households only use the solar panel. In new neighborhoods gathered in the Annexe and Ruashi municipalities, the panels use rate does not even reach $1 \%$. The purchase cost of the panels should be justified this low utilization in the suburbs, by against the high rate of access to electricity in the town of Kamalondo explain the absence of solar panels. Subsidies and improving the regulatory framework can serve as introduction programs in the market and help reduce the initial costs of deploying solar technologies and help them overcome obstacles ${ }^{25}$.

As for the use of the dynamo, it is proved that center municipalities gathering ancient districts use less dynamo. We can cite Kamalondo and Kenya municipalities followed by Lubumbashi municipality. By cons these municipalities gathering new neighborhoods are characterized by a high use rate of the dynamo. In the case of Annexe municipality where access lack is the rule, using the dynamo became the most reassuring means of assistance for these populations. This has become a business: Dynamo owner can connect up more than 
ten households that must pay $1000 \mathrm{FC}$ a day after paying the subscription fees that can reach 10000 FC. This for a serving of $6 \mathrm{~h}$ (from 17-23 h) and for limited use of bulb and electrical appliances. In Lubumbashi, this technique has become the most spread in the new districts. Faced with the shortage of electricity, small businesses in Ontario have developed genuine electric networks across neighborhoods or small towns, serving subscribers in their homes. According to a study by the World Bank, their installed capacity would represent $38 \%$ of public company ${ }^{12}$.

Apart from these different sources of energy, Lubumbashi households in case of shortage or power cut also used for lighting, flashlights, kerosene lamps and candles. It appears from this study that the candle is the more used energy source for in Lubumbashi despite its multiple damages such as fire within households. In addition these fuels generate poor quality light ${ }^{26}$.

For cooking, two main sources are used in Lubumbashi: charcoal and wood. Almost all of the surveyed households use charcoal as a source of energy for cooking and only $11 \%$ of households in the Annexe municipality use wood. This would be justified by the fact that for these suburbs, the nearby woods compared to central areas of the city facilitate the use. Urban households prefer charcoal because they do not produce a lot of smoke and heat value is twice that of wood and may last longer, especially when used with the improved stoves. Charcoal is considered relatively affordable, economical and practical ${ }^{27}$. In many places, charcoal is normally considered purchased at low cost. But due to the fact that it is repeatedly bought in small quantities, it ends up being more expensive in the long term compared to other energy sources. The energy for cooking is usually $70-90 \%$ of total energy consumption in developing countries ${ }^{28}$. It has been estimated that about 2.5 billion people in these countries depend on biomass fuels such as wood, charcoal and animal dung to meet their cooking energy needs. According to the IEA ${ }^{29}$, without substantial change in policy, the total number of people who depend on biofuels will increase $^{29}$ from 2400 in 2010 to 2700 million by 2030 . Moreover, demand for cooking fuel, especially in urban areas amplifies deforestation ${ }^{2,27}$. Poorer countries are severely deforested at rates approaching $95 \%$ and even $98 \%$, in Africa it is responsible for over $90 \%$ of the harvested wood biomass ${ }^{7}$. In addition, there are health risks linked to the use of charcoal. Indeed, when coal is burned, it produces carbon monoxide. If coal is used in a room that is not well ventilated, it could lead to high concentrations of carbon monoxide and cause a hazard to the user ${ }^{3,27,30-32}$. Besides the shortage, biofuels also affect women and children in particular, who need more time to collect these fuels, time that could be spent on other activities such as agriculture and education ${ }^{3,33}$. It is clear that lack of access to a reliable electricity system entails multiple consequences both socio-economic and environmental. The sum of costs for energy, in the context of the city of Lubumbashi, far exceeds that required for a permanent access to an electricity grid. According to the World Bank this situation tends to make the poor poorer ${ }^{12}$. The use of solar panels is less common even it produces clean and sustainable energy. Only political subsidies and improving the regulatory environment can promote the introduction of programs on the market and help reduce the initial costs of deploying solar technologies and promote this clean energy source.

\section{CONCLUSION}

The study reveals two main sources of energy for cooking, four for lighting and three as alternative sources of electricity. For every need, there is the most used source. In case of load shedding or lack of electricity, the Lubumbashi households are implementing alternative sources such as the generator, dynamo or solar panels. Although the Dynamo is less used at the urban scale, however, it is for most municipalities a reassuring source of electricity in the new neighborhoods distant from town center.

\section{SIGNIFICANCE STATEMENT}

This study reveals that to respond to the poor quality of electrical service in the city of Lubumbashi, the population resorts to collective solutions consisting of mini networks powered by a diesel group commonly called dynamo as an alternative source of access to electricity. This study also identified that access to sustainable energy sources was a function of the location of the household in relation to the city center and the dynamo-powered mini-grids provide a reassuring source in the new, remote neighborhoods of the city center. This was not yet identified and quantified by previous studies.

\section{ACKNOWLEDGMENTS}

The authors thank the Académie de Rechercheetd' Enseignement Supérieur, Commission de la Coopération au développement (ARES-CCD) for funding the research that led to the realization of this scientific work. 


\section{REFERENCES}

1. Du Toit, M.J., S.S. Cilliers, M. Dallimer, M. Goddard, S. Guenat and S.F. Cornelius, 2018. Urban green infrastructure and ecosystem services in sub-Saharan Africa. Landscape Urban Plan., 180: 249-261.

2. IEA., 2015. World Energy Outlook 2015. International Energy Agency, Paris, France, ISBN: 978-92-64-24366-8, Pages: 700.

3. Benka-Coker, M.L., W. Tadele, A. Milano, D. Getaneh and H. Stokes, 2018. A case study of the ethanol CleanCook stove intervention and potential scale-up in Ethiopia. Energy Sustainable Dev., 46: 53-64.

4. Pereira, P.S., P.A. Cerqueira and O. Wojolomi, 2019. Determinants of renewable energy growth in Sub-Saharan Africa: Evidence from panel ARDL. Energy, 156: 45-54.

5. Moner-Girona, M., M. Solano-Peralta, M. Lazopoulou, E.K. Ackom, X. Vallve and S. Szabo, 2018. Electrification of Sub-Saharan Africa through PV/hybrid mini-grids: Reducing the gap between current business models and on-site experience. Renewable Sustainable Energy Rev., 91: 1148-1161.

6. Smith, H.E., D. Jones, F. Vollmer, S. Baumert and C.M. Ryan et al., 2019. Urban energy transitions and rural income generation: Sustainable opportunities for rural development through charcoal production. World Dev., 113: 237-245.

7. Agbemabiese, L., J. Nkomo and Y. Sokona, 2012. Enabling innovations in energy access: An African perspective. Energy Policy, 47: 38-47.

8. Bonan, J., S. Pareglio and M. Tavoni, 2017. Access to modern energy: A review of barriers, drivers and impacts. Environ. Dev. Econ., 22: 491-516.

9. Kathleen, J.H., 2015. The expanding horizon of renewable energy in sub-Saharan Africa: Leading research in the social sciences. Energy Res. Social Sci., 5: 1-8.

10. Banza, B.W., K.T. Flory, P. Bouillard and D.H. Tungadio, 2018. Electricity access in Lubumbashi, DR Congo: Influence of household socioeconomic factors. Journal of American Academic Research Vol. 6, No. 1.

11. McLean, E.V., S. Bagchi-Sen, J.D. Atkinson, J. Ravenscroft, S. Hewner and A. Schindel, 2019. Country-level analysis of household fuel transitions. World Dev., 114: 267-280.

12. IEA., 2010. World Energy Outlook 2010. 1st Edn., International Energy Agency, P aris, France, ISBN: 9789264086241, Pages: 731.

13. Banza, B.B., 2018. Urbanization and Governance of the Electrical Service in DR Congo. Editions Universitaires Européennes, USA., ISBN-10: 6138446518, Pages: 204.
14. Zhao, X., J. Liang and C. Dang, 2019. A stratified sampling based clustering algorithm for large-scale data. Knowl.-Based Syst., 163: 416-428.

15. Lessard, C., 2015. L'enquete quebecoise sur l'acces a internet 2012. Présentation et Analyse des Resultats, Institut de la Statistique du Québec, Septembre 2015, pp : 1-157.

16. Jeyashree, K., R.S. Abdulkader, S. Kathirvel, P. Chinnakali and M.V.A. Kumar, 2018. Profile of and expenditure on morbidity and hospitalizations among elderly-Analysis of a nationally representative sample survey in India. Arch. Gerontol. Geriatr. 74: 55-61.

17. Laurencelle, L., 2012. [The representativeness of a sample and test by chisquare]. Tutorials Quant. Methods Psychol., 8: 173-181.

18. Wang, Y., N. Roohi, M. West, M. Viswanathan and G.E. Dullerud, 2018. Statistical verification of PCTL using stratified samples. IFAC-Papers OnLine, 51: 85-90.

19. Yakubu, O., C.N. Babu and O. Adjei, 2018. Electricity theft: Analysis of the underlying contributory factors in Ghana. Energy Policy, 123: 611-618.

20. Farinmadea, A., O. Soyinkab and K.W.M. Siu, 2018. Assessing the effect of urban informal economic activity on the quality of the built environment for sustainable urban development in Lagos, Nigeria. Sustainable Cities Soc. 41: 13-21.

21. Iwara, A. and O. Ogundele, 2018. Temporal variation in nutrient element losses in fallows of different ages Southern Nigeria. Asian J. Applied Sci., 11: 117-124.

22. Wu, S., X. Zheng, C. You and C. Wei, 2019. Household energy consumption in rural China: Historical development, present pattern and policy implication. J. Cleaner Prod. 211: 981-991.

23. Ubani, O.J., L. Umeh and L.N. Ugwu, 2013. Analysis of the electricity consumption in the south-east geopolitical region of Nigeria. J. Energy Technol. Policy, 3: 20-31.

24. Imo, C., C.D.U. Nwokwu, E. Mamma, M.H. Mayel, A.J. Kukoyi and A.D. Apaji, 2018. Effects of ethanolic extracts of Phoenix dactylifera fruit, Cyperus esculentus Nut and Cocos nucifera Nut on selected indices of kidney function in male albino rats. J. Applied Sci., 18: 116-121.

25. IEA., 2009. Cities, Towns and Renewable Energy. International Energy Agency, Paris, France, Pages: 194.

26. Mills, E., 2015. The specter of fuel-based lighting. Science, 308: 1263-1264.

27. Karekezi, S., J. Kimani and O. Onguru, 2008. Energy access among the urban poor in Kenya. Energy Sustainable Dev., 12: 38-48.

28. Puzzolo, E., D. Pope, D. Stanistreet, E.A. Rehfuess and N.G. Bruce, 2016. Clean fuels for resource-poor settings: A systematic review of barriers and enablers to adoption and sustained use. Environ. Res., 146: 218-234. 
29. IEA., 2010. World energy outlook 2010. International Energy Agency, Paris, Frence. http://large.stanford.edu/courses/ 2010/ph240/riley2/docs/EIA-0484-2010.pdf

30. Kumar, A., 2018. Justice and politics in energy access for education, livelihoods and health: How socio-cultural processes mediate the winners and losers. Energy Res. Social Sci., 40: 3-13.

31. Njong, A.M. and T.A. Johannes, 2011. An analysis of domestic cooking energy choices in Cameroon. Eur. J. Social Sci., 20: 336-347.
32. Geremew, K., M. Gedefaw, Z. Dagnew and D. Jara, 2014. Current level and correlates of traditional cooking energy sources utilization in urban settings in the context of climate change and health, northwest Ethiopia: A case of Debre Markos town. BioMed Res. Int., Vol. 2014. 10.1155/2014/572473.

33. Choumert-Nkolo, J., P.C. Mote and L. Le Roux, 2019. Stacking up the ladder: A panel data analysis of Tanzanian household energy choices. World Dev., 115: 222-235. 